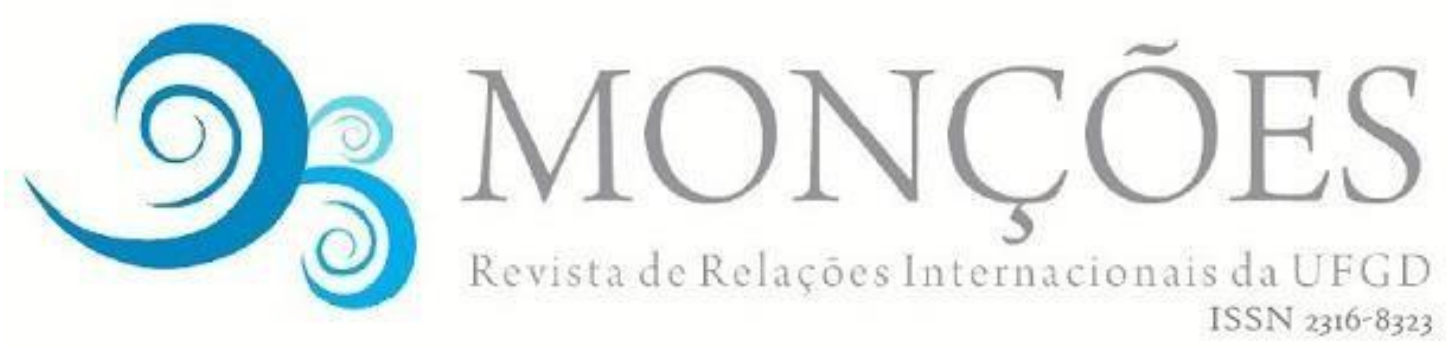

\title{
FRONTEIRAS BRASILEIRAS: EVOLUÇÃO DA AGENDA E REDES DE ATORES NO CONGRESSO NACIONAL (1990-2016)
}

\author{
SOLÈNE MARIÉ \\ Universidade de Brasília (UNB).
}

\begin{abstract}
RESUMO: Esse artigo visa responder à seguinte pergunta: Quais redes políticas podem ser identificadas ao redor do tema das fronteiras a partir da análise da evolução da agenda legislativa federal e dos atores envolvidos? Para tanto, é conduzida uma análise da trajetória destas políticas a partir do início dos anos 1990 e até o último ano completado, assim como um mapeamento dos atores envolvidos no processo com base em um enfoque de redes de políticas públicas. A hipótese da autora de que no início dos anos 2000 se produziu uma mudança de agenda de questões administrativas e de segurança para questões de desenvolvimento, foi confirmada pelo estudo empírico conduzido. A hipótese de que a pauta legislativa de fronteiras é dominada por atores oriundos da região Sul do Brasil foi verificada no sentido de que foi observada uma forte prevalência de deputados e senadores da região Sul na autoria de projetos de lei sobre fronteiras. Entretanto, não se nota uma prevalência de projetos de lei dirigidos especificamente para a região Sul. Por fim, a existência de uma ligação entre interesses relacionados à agropecuária e às fronteiras é sugerida pelo cruzamento de nomes entre os dois grupos de interesse.
\end{abstract}

PALAVRAS-CHAVE: fronteiras; Congresso Nacional; redes

\section{BRAZILIAN BORDERS: EVOLUTION OF THE AGENDA AND NETWORKS OF ACTORS IN THE NATIONAL CONGRESS (1990-2016)}

\begin{abstract}
This article aims to answer the following question: Which policy networks around the theme of borders can be identified based on the analysis of the evolution of the federal legislative agenda and of the actors involved in the process? In order to do so, a sequence analysis of these policies is conducted from 1990 to the last bygone year. Additionally, actors involved in the process are mapped based on the framework of public policy networks. The author's first hypothesis was confirmed: there was an agenda change at the beginning of the 2000s, from administrative and security issues to development issues. The second hypothesis around the dominance of actors from the Southern region of Brazil in the legislative border agenda was partially confirmed: there is a prevalence of MPs and Senators from the Southern region in the submission of bills on this theme. However, this overrepresentation of the South does not appear in terms of bills designed for a specific region. Finally, the existence of a link between interest linked to agriculture and to borders is suggested by the crossover of names between the two interest groups.
\end{abstract}

KEYWORDS: borders; National Congress; networks 


\section{Introdução}

Sendo a materialização do início e do fim do poder político estatal, fronteiras são um fenômeno fundamental no estudo da política doméstica e internacional. Entretanto, fronteiras são paradoxalmente pouco estudadas dentro do campo da Ciência Política e das Relações Internacionais, o que evidencia uma carência de referências na área (PRADO; ESPÓSITO NETO, 2015). O ainda modesto campo dos chamados Estudos Fronteiriços ${ }^{1}$ se concentra principalmente em três questões, quais sejam: o hibridismo cultural em zonas de fronteira; a integração de cidades fronteiriças; a particularidade de regiões de fronteira em relação a Estados Nacionais (ALBUQUERQUE, 2005). A questão da agenda e das políticas públicas para as regiões de fronteira é principalmente estudada em nível subnacional, razão pela qual se adotou aqui um olhar diferente, conduzindo uma análise da agenda legislativa para regiões de fronteira em nível nacional. Usualmente, não se encontra um interesse muito marcante, nos processos decisórios políticos, pela atividade legislativa e por seu peso específico no manejo de políticas públicas.

Este estudo de caso procura responder as seguintes perguntas: Como evoluiu a agenda legislativa federal de fronteiras entre 1990 e 2016 e quais foram os atores envolvidos? Quais redes políticas ao redor do tema de fronteiras podem ser identificadas a partir dessa análise? Para tanto, ele traz uma análise da trajetória destas políticas a partir do início dos anos 1990 e até o último ano completado, assim como um mapeamento dos atores envolvidos no processo e dos grupos identificados com base em um enfoque de redes de políticas públicas.

A hipótese da autora é a de que no início dos anos 2000 se produziu uma mudança de agenda de questões administrativas e de segurança para questões de desenvolvimento, que a pauta legislativa de fronteiras é dominada por atores provindos da região Sul do Brasil e que é possível supor uma ligação entre interesses ligados à agropecuária e às fronteiras.

\footnotetext{
${ }^{1}$ Border studies na denominação internacional.

Para apanhados recentes sobre o tema, ver: STAUDT, Kathleen (2017) Border Politics in a Global Era. Comparative Perspectives. Lanham: Rowman \& Littlefield Publishers. 320 p. e PRADO, Henrique Sartori de Almeida; ESPÓSITO NETO, Tomaz [org.]. Fronteiras e relações internacionais. Curitiba: Ithala, 2015.
} 


\section{Análise de redes e mudança legislativa}

Para começar e diante da multiplicidade de usos da palavra "rede" dentro de diferentes disciplinas e linhas de pensamento, é importante definir a abordagem que se tem aqui. Powell e Smith-Doerr (1994 apud CALMON; COSTA, 2013) identificam duas vertentes principais nos estudos de redes, que são relacionadas. A primeira, cujas origens estão na sociologia e na teoria das organizações, entende a noção de rede como instrumento analítico. Ele permite dar conta, de nível mais micro a nível mais macro, de aspectos relacionais dentro das organizações, entre organizações, e entre organizações e o ambiente externo a elas. A segunda vertente, cujos aportes principais provêm da administração pública, das políticas públicas e da economia, se interessa por redes como forma de governança (CALMON; COSTA, 2013). Enquanto a segunda abordagem se baseia na existência concreta de formas de organização natural e social em redes compostas por nós, a primeira é mais recente, constituindo uma capacidade de enxergar a metáfora da rede como ferramenta de análise (KOLIBA; MEEK; ZIA, 2010). Neste artigo, nosso enfoque está baseado na noção de rede como ferramenta analítica.

Abordagens pluralistas, na linha de Dahl (1956), consideram a formação da agenda como um processo competitivo aberto, no qual grupos de interesse se envolvem com o objetivo de defender seus objetivos. Embora todos não possuam os mesmos recursos, todos teriam a possibilidade de se envolver para influenciar o processo político.

Entretanto, este suposto campo político aberto e nivelado não corresponde à realidade na qual alguns grupos de interesse têm a capacidade de limitar o escopo da agenda e no qual o silêncio da população sobre determinado assunto não necessariamente significa satisfação com o status quo (BONAFONT, 2010).

Abordagens neoinstitucionalistas ${ }^{2}$, por outro lado, insistem na dimensão histórica do processo de construção das políticas públicas: atores agem com base em um legado histórico e estruturas existentes que determinam as possibilidades de formulação de ideias novas e de implementação de mudanças (BONAFONT, 2004,

\footnotetext{
${ }^{2}$ Conjunto de teorias que enxergam o papel das instituições como o de estabelecer as regras do jogo para ordenar o sistema social (NORTH, 1991).
} 
2010).

A abordagem de redes se encontra no cruzamento dessas duas vertentes, embora ela se aproxime mais dos postulados do neoinstitucionalismo. A estrutura e distribuição do poder é vista como um possível entrave à mudança de políticas, mas também como uma possível garantia de acesso à definição da agenda para outros grupos de interesse, meios de comunicação e especialistas (BONAFONT, 2004).

A abordagem de redes parte de três pressupostos: 1- o principal elemento que influencia os objetivos e as estratégias dos atores é o contexto institucional; 2- os interesses dos atores devem ser investigados porque eles não podem ser assumidos a priori e eles são múltiplos; 3- organizações públicas e movimentos sociais não são os únicos atores envolvidos no processo de construção das políticas públicas e portanto, a análise precisa ser estendida a outros protagonistas, como os grupos de especialistas e a imprensa (BONAFONT, 2004).

Ao contrário da maioria dos outros métodos que tendem a focar as suas análises nas características intrínsecas dos atores que compõem o objeto de estudo, a especificidade da abordagem de redes se encontra no seu foco em mapear e analisar os laços entre os atores (PERLIGER; BROOK; PEDAHZUR, 2011). Este aspecto contextual frequentemente menosprezado é fundamental na medida em que a estrutura das interações entre atores influencia o comportamento individual e coletivo e, portanto, as continuidades e as rupturas na condução das políticas públicas (SIEGEL, 2011).

Mecanismos causais explicando a relação entre uma rede de atores e a tomada de decisão são múltiplos. Alguns são particularmente propícios a análises quantitativas (que dominam as análises conduzidas com este método) mas outros se beneficiam mais de uma abordagem qualitativa que permite investigar em profundidade estas interações levando em conta o contexto, as normas que o regem e a construção do interesse conjunto a partir de uma multiplicidade de mecanismos (SIEGEL, 2011; LAZER, 2011).

\section{Considerações conceituais sobre a fronteira}

\subsection{Visões da fronteira: linha divisória ou zona}


Diante do silêncio conceitual em relação a fronteiras dentro do campo da Ciência Política e das Relações Internacionais, precisamos nos voltar para a geografia e em particular para a geopolítica, para encontrar a literatura que primeiro conceitualizou estas questões e conduziu a reflexão que acabou guiando a elaboração das políticas públicas nesse campo.

Na visão de um dos "pais" da geopolítica, Rudolf Kjéllen, Estados seriam comparáveis a seres sensíveis. Portanto, as fronteiras, como a epiderme de um ser vivo, constituiriam uma linha divisória entre o ambiente interno e externo e seriam o primeiro receptor de fenômenos provindo do ambiente externo e dirigidos até o "cérebro estatal" (SCHERMA, 2015). Nesta perspectiva, prevalente durante muito tempo, a fronteira é vista como limite, como linha divisória, e por esta razão possui uma importância fundamental em termos de segurança.

Contudo, esta visão não é a única existente na literatura. Ela convive com uma visão mais recente que encara fronteiras como territórios que respondem a uma lógica própria e portanto, tem que ser entendidas em termos de zona (MACHADO, 1998). Uma fronteira é um espaço fundamentalmente transitório:

(...) os limites entre as nacionalidades se caracterizam por uma faixa de transição onde os valores de cada parte, particularmente a língua, raça, religião, ideologia, costumes e comércio, se interpenetram. (...) Se a caracterização jurídica da fronteira é a linha, a sua realidade cultural ou administrativa (instalação de postos de controle, alfândegas, elementos de vigilância ou defesa) é a faixa (MEIRA MATTOS, 1990, p. 34 apud SCHERMA, 2015)

\subsection{Definições: fronteira, faixa de fronteira, região de fronteira e zona de fronteira}

Dentro destas duas visões gerais da fronteira como linha divisória ou como zona devem ser feitas algumas distinções conceituais para entender corretamente as várias denominações que são usadas para se referir ao fenômeno: fronteira, faixa de fronteira, região de fronteira e zona de fronteira.

A origem histórica da palavra "fronteira" mostra que ela nasceu não como conceito político mas como fenômeno da vida social: etimologicamente, ela remete ao que "está na frente", representando a margem do mundo habitado (MACHADO, 1998). Desta forma, ela corresponde a uma realidade humana que foi experimentada pelos povos até antes da criação dos Estados modernos e da adoção do princípio de 
soberania.

A faixa de fronteira é uma área que pode ser estabelecida por um Estado "para direcionar um tratamento político diferenciado em relação ao restante do país" (FURTADO, 2011, p. 31). Na América Latina, esta distinção jurídica é feita por seis países: Brasil, Uruguai, Paraguai, Bolívia, Peru e Equador. Apesar da constatação de que a existência de uma faixa de fronteira é geralmente associada a questões de segurança nacional, o tamanho desta faixa e as normas conexas a ela não têm padrão e são definidos individualmente por cada Estado (FURTADO, 2011). Assim, a faixa de fronteira corresponde a uma realidade jurídica.

Uma região de fronteira corresponde, em uma perspectiva nacional, a uma área na qual se concentram fluxos transfronteiriços. Por fim, uma zona de fronteira é a junção de duas ou mais regiões de fronteira de países limítrofes (STEIMAN, 2002). Furtado (2011, p. 35) define esta zona de fronteira de forma mais precisa como sendo "um espaço geográfico construído pelas próprias redes e fluxos fronteiriços, o qual pode variar conforme o efeito resultante do contato entre os países". Logo, regiões e zonas de fronteira são definidas pelas interações.

Recapitulando, o conceito de fronteira tem uma origem social, o conceito de faixa de fronteira é jurídico e os conceitos de zona e de região de fronteira são baseados em interações. Estudando Políticas Públicas para a fronteira, precisamos entender e diferenciar estes conceitos na medida em que deles decorrem visões diferentes da fronteira e consequentemente, políticas diferentes.

Neste artigo, tomamos a fronteira no sentido jurídico, enquanto faixa, o que Ihe confere realidade formal e, portanto, se faz presente nestes termos no debate legislativo.

\subsection{Fronteiras e redes}

A observação da existência de fluxos e redes transfronteiriços (a ordem espontânea), que em alguns casos é formalizada pelo Estado (a ordem organizada), tem como efeito uma mudança da perspectiva do Estado sobre fronteiras e sobre a lei territorial de uma maneira geral. Podem ser criadas legislações específicas para responder a necessidades ou projetos regionais, como zonas francas, zonas de livre comércio e portos secos, no caso brasileiro. Estas iniciativas acentuam ou criam 
territorialidades especiais, distintas da lei territorial nacional (MACHADO, 1998).

Seria errado opor a imaterialidade das redes e a materialidade do território, concluindo que um não tem a capacidade de afetar o outro. Como argumentado por Raffestin (1981 apud MACHADO, 1998), redes são uma das variáveis que contribuem para a produção e delimitação do território, quer elas sejam naturais, infraestruturais, transacionais ou informacionais. Desta forma, o entendimento da lógica das zonas de fronteira é indissociável do entendimento do funcionamento de redes.

Entretanto, apesar da conexão forte entre espaços de fronteira e a noção de rede, o estudo das interações transfronteiriças não é o objeto aqui. A temática das redes não será incluída nesse estudo como fenômeno fronteiriço nem como forma de governança, mas será usada como ferramenta analítica no estudo do processo legislativo.

\section{Metodologia}

O objetivo deste artigo é, em um primeiro momento, de conduzir um mapeamento da produção legislativa ao redor do tema das fronteiras, entre 1990 e 2016. Esse mapeamento tem várias dimensões: 1- uma dimensão temporal; 2- uma dimensão de conteúdo; 3- uma dimensão espacial; 4- uma dimensão política.

Com este intuito, foram levantados dados legislativos ${ }^{3}$ para identificar os projetos de lei submetidos na Câmara dos Deputados e no Senado no período escolhido. Foram compilados os seguintes dados: nome do projeto de lei; ano; nome do autor do projeto; partido do autor; Unidade Federativa (UF) do autor; ementa do projeto; região abrangida; categoria de assunto; última movimentação. Com base neste levantamento e em conjunto com a literatura brasileira sobre fronteiras, foi produzido em um segundo tempo um estudo de caso de natureza qualitativa visando a identificar a atuação de redes políticas por trás da atividade legislativa federal ao redor do tema de fronteiras.

Foram usadas duas ferramentas: a análise de trajetória (PIERSON, 2004) como suporte do trabalho de mapeamento; e a análise de redes (BONAFONT, 2004;

\footnotetext{
${ }^{3}$ Dados levantados pela autora na Rede de Informação Legislativa e Jurídica. Disponível em: <www.lexml.gov.br>. Acessado em Maio de 2017.
} 
KOLIBA; MEEK; ZIA, 2010; CALMON; COSTA, 2013; LAZER, 2011) como base para a identificação dos grupos atuantes ao redor do tema de fronteiras.

Diante da escassez da literatura sobre o tema estudado aqui, uma análise de redes de natureza qualitativa é mais apropriada e se apresenta como um primeiro esforço para mapear o fenômeno. Com base neste trabalho, poderão ser desenvolvidos outros estudos investigando com mais profundidade os laços entre os atores da rede.

O período de 1990 a 2016 foi escolhido por ser abrangente o suficiente para permitir um exame cuidadoso da questão. O período começa em 1990 porque a atividade legislativa ao redor de temas fronteiriços começou naquela década e, fora a definição da faixa de fronteira, a atividade legislativa prévia era muito baixa para tornar valioso um estudo anterior. Além disto, a atividade legislativa só pode ser analisada posteriormente à volta da democracia em 1988. O período termina em 2016 por ser o último ano completo possível de analisar.

Por fim, várias razões motivam a escolha do caso e da abordagem. Primeiro, a literatura sobre fronteiras é incipiente dentro do campo da Ciência Política no mundo em geral e no Brasil em particular. Segundo, a maioria dos estudos sobre fronteiras no Brasil são conduzidos desde uma perspectiva local, o que os tornam muito específicos devido à variedade de tipos de fronteiras existentes no Brasil (desde fronteiras pouco povoadas e pautadas por questões ambientais e indígenas na Amazônia; até fronteiras bastante povoadas no sul do país, onde existe uma interação e um comércio nas fronteiras). Por fim, as questões ligadas à atuação do executivo neste campo já foram mais aprofundadas ${ }^{4}$ do que o papel do legislativo.

Por isso, escolheu-se adotar uma perspectiva nacional e focada no processo legislativo.

\section{Fronteiras brasileiras}

\subsection{Apresentação das fronteiras brasileiras}

Além de ser o maior país da América do Sul em extensão territorial, o Brasil também compartilha fronteiras com o maior número de vizinhos: dez países. As

\footnotetext{
${ }^{4}$ Principalmente a través do trabalho de Renata Furtado. Ver FURTADO, 2011 e FURTADO, 2013.
} 
fronteiras marítimas do Brasil somam 7.367 quilômetros (MOREIRA et al., 2008) e as fronteiras terrestres totalizam 16.886 quilômetros (LOSADA; SADECK, 2015).

A faixa de fronteira brasileira totaliza uma área de aproximadamente 2,3 milhões de quilômetros quadrados (MOREIRA et al., 2008), representando quase $27 \%$ do território nacional, na qual moram dez milhões de habitantes (BRASIL, 2011).

Esta faixa de fronteira reúne 588 municípios (BRASIL, 2005), ou seja, 10\% das cidades brasileiras. Elas estão distribuídas nos seguintes onze estados das regiões Norte: Rondônia (27), Acre (22), Amazonas (21), Amapá (8), Roraima (15), Pará (5); Centro-Oeste: Mato Grosso (28), Mato Grosso do Sul (44); e Sul: Rio Grande do Sul (197), Santa Catarina (82), Paraná (139) (LOSADA; SADECK, 2015). É de se notar que a maioria dos municípios fronteiriços está localizada na região Sul.

Estes municípios são divididos em duas categorias. Primeiro, os municípios lindeiros incluem: municípios fronteiriços cuja sede se situa na linha de fronteira (podendo ou não ser acoplados com um município do país vizinho na forma de cidades-gêmeas); municípios fronteiriços cuja sede não se situa na linha de fronteira; e municípios fronteiriços cuja sede não se situa na faixa de fronteira. Segundo, os municípios não-lindeiros se situam na retaguarda da faixa de fronteira e incluem: municípios cuja sede se situa dentro da faixa de fronteira; e municípios suja sede se situa fora dela (BRASIL, 2005, p. 11). As fronteiras brasileiras apresentam uma grande heterogeneidade, com municípios de grande tamanho no arco norte e logo uma proporção mais alta de municípios pertencendo à categoria de municípios nãolindeiros com sede fora da faixa de fronteira; e um arco sul com municípios menores e um maior número de cidades-gêmeas (BRASIL, 2005).

\subsection{Marco jurídico para as fronteiras brasileiras}

Dando uma visão geral do dispositivo federal para fronteiras, podemos dizer que, hoje, o regime de fronteiras é composto de um conjunto de leis, decretos-leis, decretos e decretos legislativos.

A atual faixa de fronteira brasileira é o resultado de um longo processo histórico, que remonta aos tempos da Colônia. Inicialmente estabelecida em dez léguas (sessenta quilômetros) e sucessivamente modificada em 1934, 1937 e 1946, o seu tamanho atual de 150 quilômetros de largura paralelos à linha divisória nacional 
foi consolidado através da Lei n. 6.634 de 1979, do Decreto n. 85.064 de 1980, recebidos pela Constituição Federal de 1988 (MOREIRA et al., 2008; LOSADA; SADECK, 2015). Este marco jurídico foi estabelecido com base na importância desta área em termos de segurança nacional.

Além da faixa de fronteira, vista como um espaço estratégico de defesa desde tempo antigos e que se aplica a todas as fronteiras nacionais, desenvolveu-se mais recentemente uma visão da fronteira como espaço de integração. Isso levou à criação de uma zona de integração fronteiriça na região Sul do país. Estabelecida em 2002 através do acordo entre Brasil e Uruguai para Permissão de Residência, Estudo e Trabalho a Nacionais Fronteiriços Brasileiros e Uruguaios e formalizada pelo Decreto № 5.105 de 2004, ela corresponde a uma área de vinte quilômetros na qual ambos países concedem benefícios às comunidades residentes, consideradas fronteiriças (FURTADO, 2011).

Como estabelecido na Constituição vigente, o órgão responsável pela aplicação das leis na faixa de fronteira em termos de trânsito, de ocupação territorial e de exploração econômica é o Conselho de Defesa Nacional (CDN) (LOSADA; SADECK, 2015).

Podemos distinguir duas fases na evolução do marco jurídico para as zonas de fronteira. A primeira corre de 1955, com a lei 2.597 sobre zonas indispensáveis à defesa do país, até 1999, com a modificação da lei 9.871 sobre alienação de terras na faixa de fronteira. Ela corresponde à construção do arcabouço legal para as fronteiras. A segunda fase corre de 2000 até hoje e é marcada por uma crescente proatividade legislativa em termos de temas fronteiriços e, embora as questões de segurança não tenham perdido importância, deu-se uma abertura da agenda legislativa para questões de desenvolvimento regional para as fronteiras, tais como desenvolvimento econômico, infraestrutura, vigilância sanitária e exercício da cidadania. Dentro desta segunda fase, dois momentos a destacar são o período de 2004 a 2008, que marcou uma transição para questões de desenvolvimento, e o ano de 2012, no qual foi votada a Lei 12.723 que regula a instalação de lojas francas na faixa de fronteira e em cidades-gêmeas (BRASIL, 2013). 


\section{Estudo dos projetos de leis sobre fronteiras em tramitação no congresso} nacional e mapeamento dos atores envolvidos

Com base no levantamento de dados conduzido pela autora na Rede de Informação Legislativa e Jurídica ${ }^{5}$, foram produzidos gráficos que permitem identificar e ilustrar várias tendências. Serão destacadas tendências em termos de evolução de número de projetos de lei sobre fronteiras; de categoria de assunto fronteiriço tratado pelo projeto; de região de origem e de partido dos deputados e senadores envolvidos nessas questões; e de regiões abrangidas pelos projetos.

\subsection{Projetos dedicados ao tema das fronteiras de 1990 a 2016}

O gráfico a seguir evidencia a evolução do número de projetos de lei submetidos no Congresso Nacional sobre o tema das fronteiras entre 1990 e 2016:

\section{Gráfico 1: Número de projetos de lei sobre a faixa de fronteira submetidos no Congresso Nacional (1990-2016)}

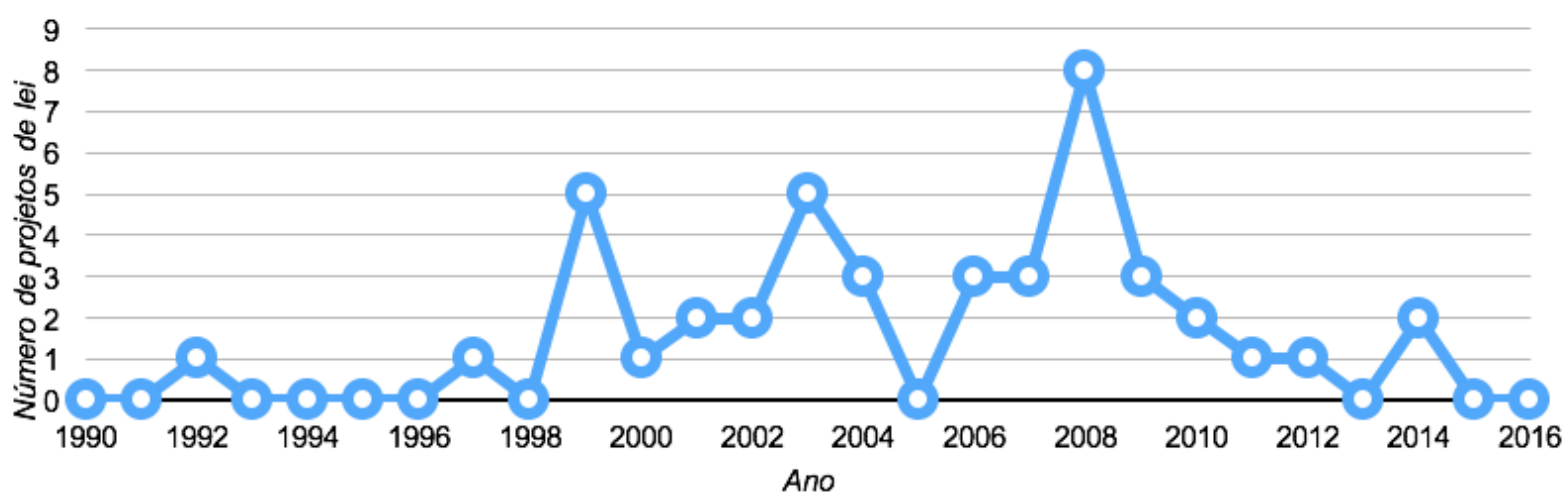

Elaboração da autora a partir de dados coletados em: Rede de Informação Legislativa e Jurídica

Com base neste gráfico, podemos tirar algumas conclusões. Aparecem três fases em termos de número de projetos. Uma primeira fase, de 1990 a 1998, foi marcada por um baixo número de projetos sobre o tema (entre 0 e 1 dependendo dos

\footnotetext{
${ }^{5}$ Disponível em: 〈www.lexml.gov.br>. Acessado em Maio de 2017.
} 
anos), ilustrando um aparente desinteresse no tema. Na segunda fase, de 1999 a 2009, identificamos um aumento importante no número de projetos de lei (exceto no ano de 2005 no qual não houve projeto de lei sobre o tema) mostrando um foco maior em temas fronteiriços neste período. A média de projetos por ano neste intervalo corresponde a 3.2 e identificamos picos de 5 projetos em 1999, de 5 projetos em 2003, e de 8 projetos em 2008. Este último ano recebeu o maior número de projetos de lei no nosso período de estudo. Por fim, uma terceira fase que se estende de 2010 até 2016 (o final do nosso período de estudo) marca uma aparente queda do envolvimento do legislativo nos temas fronteiriços, com um máximo de 2 projetos por ano nesse intervalo de tempo.

\subsection{Evolução dos assuntos tratados dentro do tema das fronteiras}

Seguem três gráficos que visam evidenciar, por década, a importância dada aos diferentes assuntos relevantes em termos de fronteiras. O primeiro corresponde ao período de 1990 a 1999; o segundo de 2000 a 2010; e o terceiro de 2010 até o final do nosso período estudo, 2016. 


\section{Gráfico 2: Categorias de assuntos tratados nos projetos de lei sobre fronteiras,} por década (1990-1999; 2000-2010; 2010-2016)

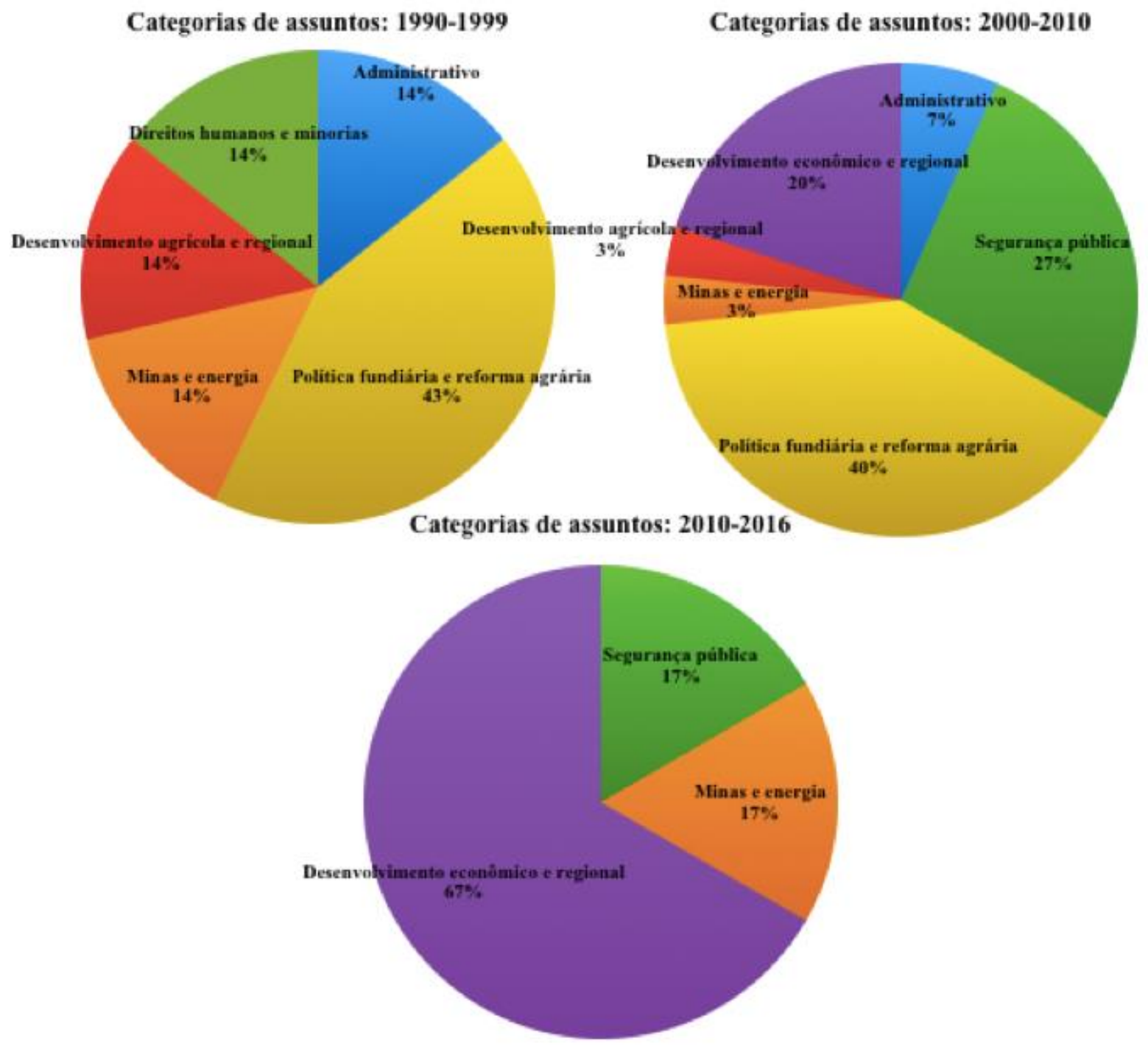

Elaboração da autora a partir de dados coletados em: Rede de Informação Legislativa e Jurídica

De uma forma geral, esses gráficos mostram um envolvimento em um número médio de temas na primeira década, que aumentou na segunda e diminuiu na terceira a um nível menor do que na primeira.

Na primeira década, é de se notar a alta prevalência de assuntos de política fundiária e de reforma agrária, representando quase a metade dos projetos de lei. Quatro outros temas foram representados de maneira igual: assuntos administrativos; de direitos humanos e minorias; de desenvolvimento agrícola e regional; e de minas 
e energia. A junção dos projetos de lei na área da política fundiária e na área administrativa mostra que essa década representou o estabelecimento do marco legal para as fronteiras brasileiras, corroborado em Brasil (2013).

$\mathrm{Na}$ segunda década, apareceram o assunto do desenvolvimento econômico e regional assim como da segurança pública. Um estudo detalhado dos projetos de lei nesta última categoria mostra que dentro do período de 2000 a 2010, 7 dos 8 projetos na área da segurança foram focados na redução do tamanho da faixa de fronteira brasileira. Isso demonstra um interesse acentuado na questão durante esse década, por parte de vários deputados e senadores. Concomitantemente, os assuntos fundiários e administrativos perderam espaço (caindo respectivamente a $40 \%$ e $7 \%$ dos projetos de lei).

$\mathrm{Na}$ terceira década, o desenvolvimento econômico e regional conheceu uma alta significativa, chegando a $67 \%$ dos projetos de lei sobre fronteiras. Podemos dizer que, de maneira geral, enquanto o assunto do desenvolvimento agrícola e regional recuou ao longo do período - de 14\% entre 1990 e 1999, para 3\% entre 2000 e 2010 , até $0 \%$ entre 2010 e 2016 - o tema do desenvolvimento econômico e regional cresceu em importância - indo de 0\% entre 1990 e 1999, para 20\% entre 2000 e 2010, para $67 \%$ entre 2010 e 2016. Esta evolução sugere que assuntos de desenvolvimento regional passaram de uma ligação com questões agrícolas para questões econômicas.

Segue um gráfico que mostra de maneira mais detalhada, por ano, a repartição dos projetos de lei em categorias de assuntos. 
Gráfico 3: Evolução do número de projetos de lei e das categorias de assuntos (1990-2016)

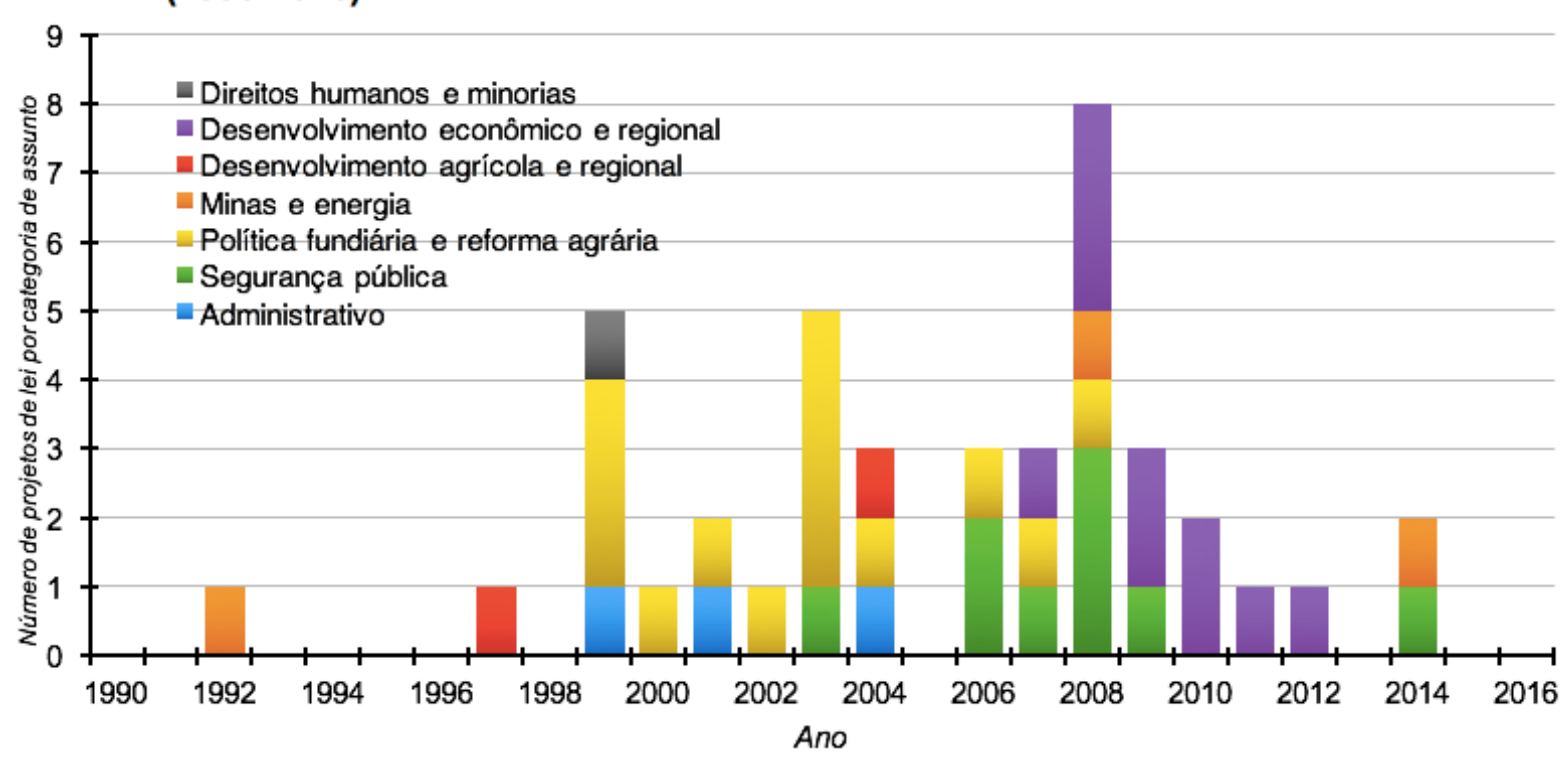

Elaboração da autora a partir de dados coletados em: Rede de Informação Legislativa e Jurídica

Este gráfico evidencia muito claramente a quase ausência de preocupação com as temáticas fronteiriças até 1999, com um pico muito grande no ano em questão. Ele evidencia também a prevalência de questões fundiárias e agrícolas no início do período, com uma passagem gradual para questões de desenvolvimento econômico. Apesar desta transição para questões de desenvolvimento econômico, vale notar que questões de segurança e de política fundiária se mantém presentes até o final do período, mesmo a níveis menores. Isso demonstra que estas questões não desapareceram da pauta com a entrada de novos temas.

\subsection{Atividade legislativa sobre fronteiras e geografia brasileira}

Seguem gráficos que mostram a repartição dos projetos de lei por Unidade Federativa do proponente principal, em número de projetos e em porcentagem do número total de projetos. 


\section{Gráfico 4: Unidade Federativa do proponente principal do projeto de lei (1990- 2016) (em número de projetos e em porcentagem do total de projetos)}
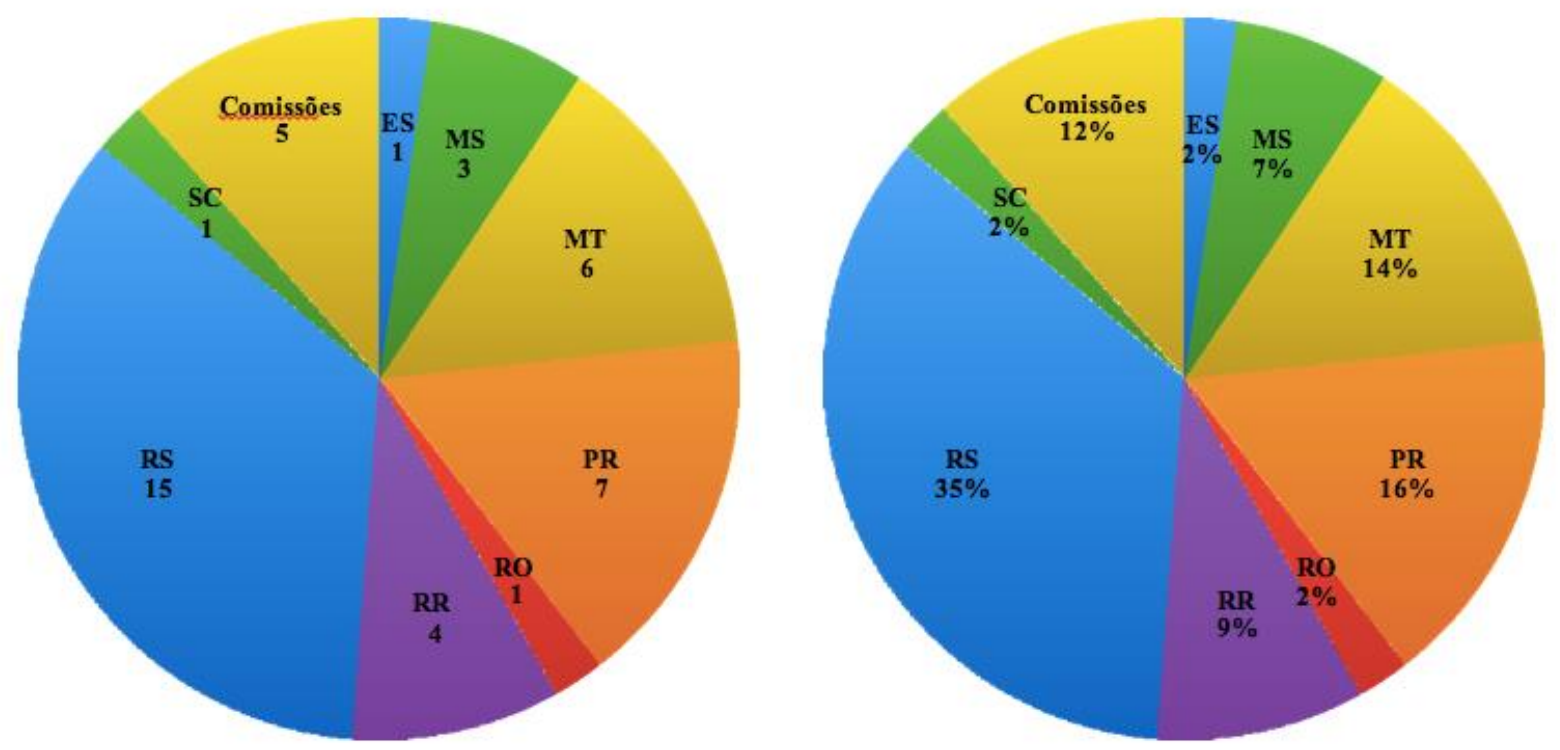

Elaboração da autora a partir de dados coletados em: Rede de Informação Legislativa e Jurídica

Este gráfico nos mostra algumas informações interessantes. Primeiro, como pode ser esperado, quase todos os Estados representados no gráfico são Estados fronteiriços, exceto o Espírito Santo, que não tem fronteira terrestre com outro país. Notamos também a presença muito forte de Estados da região Sul (53\% dos projetos), a representação menor de Estados da região Centro-Oeste (21\%) e a pouca presença de projetos provindos da região Norte $(11 \%)$. De uma maneira geral, os Estados mais presentes no debate ao redor de questões fronteiriças são o Rio Grande do Sul (RS), o Paraná (PR) e o Mato Grosso (MT). O Rio Grande do Sul chega a apresentar $35 \%$ dos projetos de lei sobre o tema, com uma proporção atual de representantes no Congresso Nacional de menos de $6 \%$ do total dos membros ${ }^{6}$. Dentro da região Norte, o Estado mais envolvido é Roraima (RR).

O gráfico seguinte representa a distribuição das regiões abrangidas pelos projetos de lei.

\footnotetext{
631 deputados e 3 senadores, do total de 594 membros (513 na Câmara dos Deputados, 81 no Senado).
} 


\section{Gráfico 5: Região abrangida pelos projetos de lei (1990-2016)}

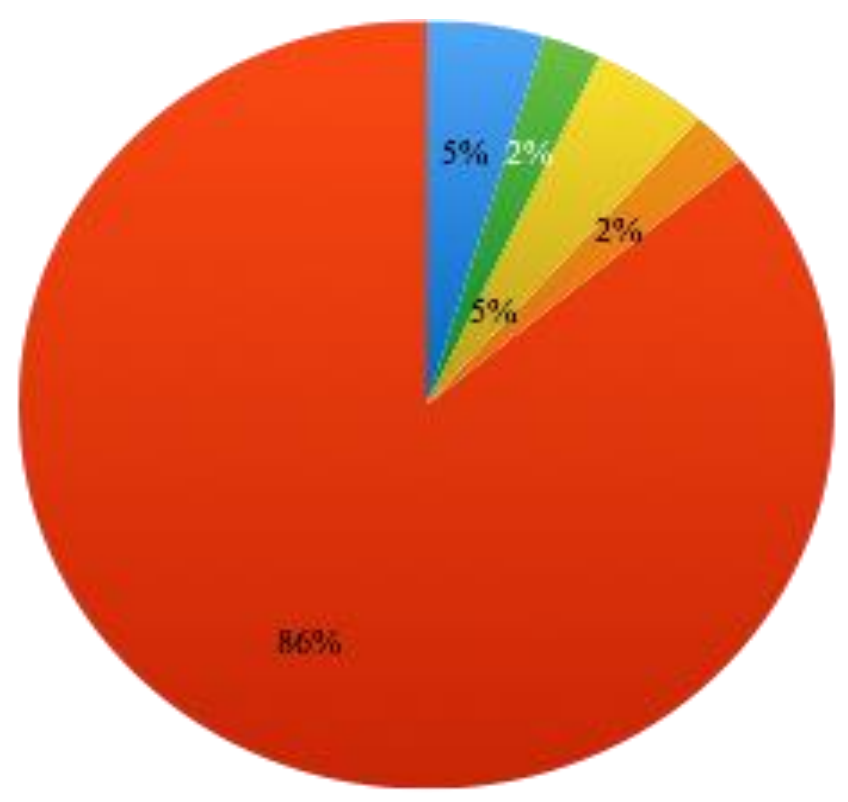

Fronteira Norte

Fronteira Norte e território nacional

Fronteira Sul

Fronteiras Norte e Oeste

Território nacional

Elaboração da autora a partir de dados coletados em: Rede de Informação Legislativa e Jurídica

Em contraste com o gráfico anterior, este não mostra uma prevalência da região Sul. Apesar de estar mais presente no debate legislativo em torno dessas questões, a região só é objeto específico de $5 \%$ dos projetos. Ao contrário, a região Norte, apesar de pouca presença no processo legislativo, é destinatária específica de 9\% dos projetos. Portanto, a maioria dos projetos de lei têm como alvo as fronteiras do território brasileiro em geral: $86 \%$ dos projetos não estão direcionados a uma região ou uma fronteira específica. O fato da região Sul ser proponente de $53 \%$ dos projetos e alvo específico só de $5 \%$ sugere que eles não se destinam primeiramente à base eleitoral do proponente e, portanto, possa existir outras lógicas explicativas.

\subsection{Atividade legislativa sobre fronteiras e partidos políticos}

Tem-se a seguir um gráfico que mostra a divisão dos partidos envolvidos na redação de projetos de lei sobre o tema das fronteiras submetidos ao Congresso Nacional. 


\section{Gráfico 6: Partido do autor do projeto de lei (1990-2016)}

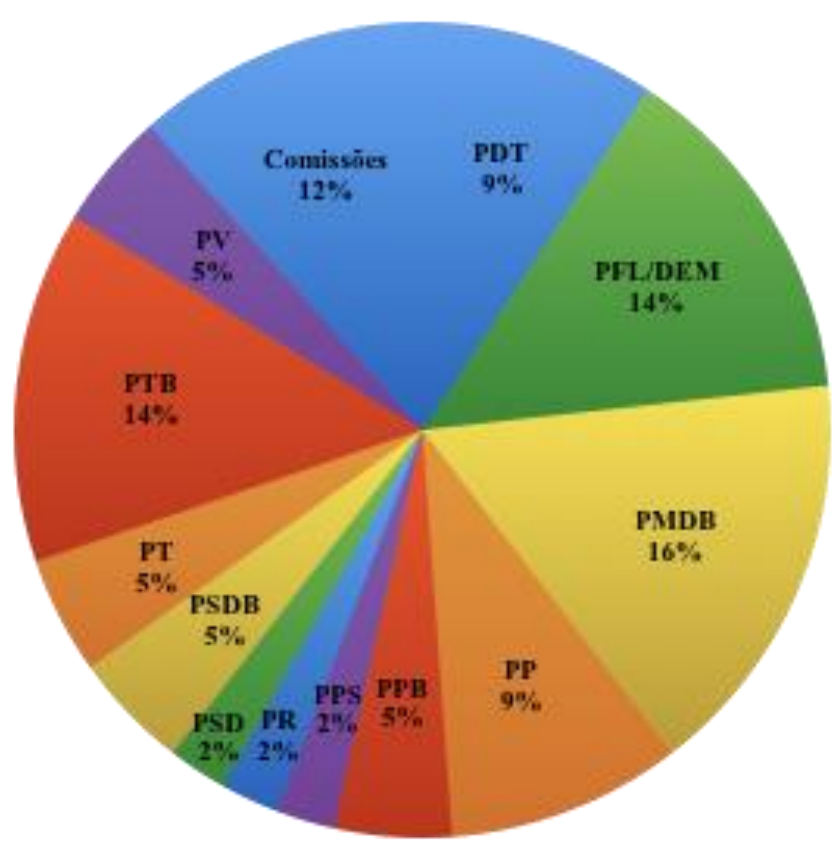

Elaboração da autora a partir de dados coletados em: Rede de Informação Legislativa e Jurídica

Este gráfico mostra que os três partidos mais envolvidos em temas fronteiriços no legislativo são o PMDB (com 16\% dos projetos); o PTB (com 14\%); e o PFL/DEM ${ }^{7}$ (14\%). O gráfico também mostra a importância de projetos liderados por comissões nesta área. Um estudo detalhado dos dados levantados pela autora também mostra a recorrência de alguns nomes de deputados e senadores em vários projetos de lei, indicando um envolvimento específico de um grupo de atores em questões fronteiriças. Esta questão será analisada em mais profundidade adiante.

Por fim, uma análise da tabela resultante do levantamento de dados conduzido pela autora evidencia que, dos 43 projetos de lei identificados, só um foi impulsionado no contexto do Mercosul ${ }^{8}$. O tema em questão, sendo eminentemente internacional e tendo um potencial muito grande para a criação de políticas públicas em contexto intergovernamental, pode ser revelador da perspectiva que se tem sobre fronteiras, no legislativo. Com base nas distinções conceituais feitas previamente, podemos dizer que a visão da fronteira como linha divisória ainda prevalece sobre a visão da fronteira como zona, embora esta segunda visão tenha se desenvolvido a

\footnotetext{
${ }^{7}$ O Partido da Frente Liberal (PFL) foi refundado em março de 2007 sob o nome de partido Democratas (DEM).

${ }^{8}$ PLS 313/2008 Mercosul
} 
partir do início dos anos 2000. Olhando este fato em uma perspectiva de governança multinível e de suas consequências sobre as estratégias dos atores em termos de venue shopping ${ }^{9}$, também pode ser um sinal da fraqueza do Mercosul como organização portadora deste tipo de projetos, o que induz os atores a procurarem outros espaços para discutir essas questões.

\section{Fronteiras e redes de atores}

Após esse mapeamento da produção legislativa ao redor do tema das fronteiras em termos de conteúdo, território e partidos políticos, é possível conduzir uma análise visando a identificar os atores e grupos envolvidos no processo (os nós na rede) assim como os vínculos entre eles (os laços na rede). A abordagem de redes sobre a qual esta análise é baseada nos fornece o quadro teórico para a visualização do processo legislativo como um processo plural, engajando uma variedade de atores e de interesses cruzados.

O primeiro elemento importante a ser destacado é a inexistência, atualmente, de uma comissão permanente dedicada à temática das fronteiras no legislativo brasileiro $^{10}$, assim como de uma frente parlamentar sobre o tema. Existiram, pontualmente, frentes parlamentares dedicadas a temáticas fronteiriças no legislativo, mas nenhuma teve uma duração de mais de um ano. O gráfico seguinte detalha a existência dessas frentes ${ }^{11}$.

\footnotetext{
${ }^{9}$ A fragmentação dos processos de tomada de decisão entre organizações diferentes da a possibilidade a grupos de interesse de escolher, entre elas, a organização que oferece a resposta que melhor corresponde aos seus interesses. Esta escolha é chamada de venue shopping (BONAFONT, 2010).

${ }^{10}$ Contrário ao Executivo, no qual atua a Comissão Permanente para o Desenvolvimento da Faixa de Fronteira (CDIF). Ela foi criada por Decreto em 2010 para contribuir para o desenvolvimento das políticas públicas para a Faixa de Fronteira. Ela é formada por 20 órgãos do governo federal e 8 entidades convidadas, que atuam sob a liderança da Secretaria de Desenvolvimento Regional do Ministério da Integração Nacional.

${ }^{11}$ Dados disponíveis a partir de 2003. A obrigatoriedade de inscrição em frentes parlamentares foi instituída só em 2006.
} 
Tabela 1: Frentes parlamentares sobre fronteiras por legislatura (52a a 55a)

\begin{tabular}{|l|l|l|l|}
\hline Legislatura & $\begin{array}{l}\text { Frente parlamentar sobre temas } \\
\text { fronteiriços }\end{array}$ & $\begin{array}{l}\text { Data de } \\
\text { criação }\end{array}$ & Coordenador/Presidente \\
\hline 52a (2003-2006) & Municípios da Faixa de Fronteira & $14 / 07 / 2005$ & $\begin{array}{l}\text { Deputado Vander Luiz dos } \\
\text { Santos Loubet (PT/MS) }\end{array}$ \\
\hline 53a (2007-2010) & Nenhuma & & \\
\hline 54a (2011-2014) & $\begin{array}{l}\text { Frente Parlamentar Mista para o } \\
\text { Desenvolvimento de Assuntos da Faixa } \\
\text { de Fronteira }\end{array}$ & $13 / 02 / 2014$ & $\begin{array}{l}\text { Deputado Marco Aurélio } \\
\text { Spall Maia (PT/RS) }\end{array}$ \\
\hline 55a (2015-2017) & Nenhuma & & \\
\hline
\end{tabular}

Elaboração da autora a partir de dados coletados em: CONGRESSO NACIONAL. Frentes Parlamentares. Disponível em: <http://www.camara.leg.br/internet/deputado/frentes.asp $>$.

Acessado em 10 de Agosto de 2017

Devido a essa inexistência de um grupo de interesse claramente identificável ao redor do tema, a importância de conduzir uma análise empírica no intuito de mapear a rede de atores envolvidos se torna maior.

O gráfico seguinte faz um recorte dos projetos de lei apresentados ao longo de período, destacando o nome, partido e UF do autor, a região abrangida e o assunto.

Tabela 2: Projetos de lei por autor, região abrangida e assunto (1990-2016)

\begin{tabular}{|c|c|c|c|c|c|}
\hline PROJETO & AUTOR & PARTIDO & UF & $\begin{array}{c}\text { REGIÃO } \\
\text { ABRANGIDA }\end{array}$ & ASSUNTO \\
\hline PL 6460/2013 & $\begin{array}{l}\text { Comissão de } \\
\text { Relações Exteriores } \\
\text { e Defesa Nacional - } \\
\text { Senado }\end{array}$ & & & $\begin{array}{l}\text { Amazônia e } \\
\text { território nacional }\end{array}$ & $\begin{array}{l}\text { Desenvolvimento } \\
\text { econômico e } \\
\text { regional }\end{array}$ \\
\hline PLS 398/2014 & $\begin{array}{l}\text { Comissão de } \\
\text { Serviços de } \\
\text { Infraestrutura - } \\
\text { Senado }\end{array}$ & & & Território nacional & $\begin{array}{l}\text { Econômico - Minas } \\
\text { e energia }\end{array}$ \\
\hline $\begin{array}{l}\text { PL CN (Conversão) } \\
8 / 1999\end{array}$ & $\begin{array}{l}\text { Comissão mista - } \\
\text { Senado }\end{array}$ & & & Território nacional & Administrativo \\
\hline PL 6191/2002 & $\begin{array}{l}\text { Comissão } \\
\text { Parlamentar de } \\
\text { Inquérito destinada } \\
\text { a investigar a } \\
\text { ocupação de terras } \\
\text { públicas na Região } \\
\text { Amazônica }\end{array}$ & & & Amazônia & $\begin{array}{l}\text { Econômico - } \\
\text { Política fundiária e } \\
\text { reforma agrária }\end{array}$ \\
\hline
\end{tabular}




\begin{tabular}{|c|c|c|c|c|c|}
\hline PL 3321/2008 & $\begin{array}{l}\text { Deputado Afonso } \\
\text { Hamm }\end{array}$ & $\mathrm{PP}$ & RS & Território nacional & $\begin{array}{l}\text { Desenvolvimento } \\
\text { econômico e } \\
\text { regional }\end{array}$ \\
\hline PLP 151/2004 & $\begin{array}{l}\text { Deputado Alceste } \\
\text { Almeida }\end{array}$ & PMDB & $\mathrm{RR}$ & Território nacional & $\begin{array}{l}\text { Desenvolvimento } \\
\text { agrícola e regional }\end{array}$ \\
\hline PL 3068/2008 & $\begin{array}{l}\text { Deputado Carlos } \\
\text { Bezerra }\end{array}$ & PMDB & MT & Território nacional & Segurança pública \\
\hline PL 6728/2006 & $\begin{array}{l}\text { Deputado Carlos } \\
\text { Humberto Mannato }\end{array}$ & PDT & $\mathrm{ES}$ & Território nacional & $\begin{array}{l}\text { Econômico - } \\
\text { Política fundiária e } \\
\text { reforma agrária }\end{array}$ \\
\hline PEC 23/2003 & $\begin{array}{l}\text { Deputado Eduardo } \\
\text { Sciarra }\end{array}$ & PFL & PR & Território nacional & Segurança pública \\
\hline PL 3082/2008 & $\begin{array}{l}\text { Deputado Homero } \\
\text { Pereira }\end{array}$ & PR & MT & Território nacional & $\begin{array}{l}\text { Econômico - } \\
\text { Política fundiária e } \\
\text { reforma agrária }\end{array}$ \\
\hline PL 7860/2014 & $\begin{array}{l}\text { Deputado João } \\
\text { Rodrigues }\end{array}$ & PSD & $\mathrm{SC}$ & Território nacional & Segurança pública \\
\hline PLC 90/2012 & $\begin{array}{l}\text { Deputado Luis } \\
\text { Carlos Heinze }\end{array}$ & PP & $\mathrm{RS}$ & Território nacional & $\begin{array}{l}\text { Econômico - } \\
\text { Política fundiária e } \\
\text { reforma agrária }\end{array}$ \\
\hline PLC 90/2012 & $\begin{array}{l}\text { Deputado Luis } \\
\text { Carlos Heinze }\end{array}$ & PP & $\mathrm{RS}$ & Território nacional & $\begin{array}{l}\text { Econômico - } \\
\text { Política fundiária e } \\
\text { reforma agrária }\end{array}$ \\
\hline PLC 11/2012 & $\begin{array}{l}\text { Deputado Marco } \\
\text { Maia }\end{array}$ & PT & $\mathrm{RS}$ & Território nacional & $\begin{array}{l}\text { Desenvolvimento } \\
\text { econômico e } \\
\text { regional }\end{array}$ \\
\hline PL 2275/2007 & $\begin{array}{l}\text { Deputado Matteo } \\
\text { Chiarelli }\end{array}$ & DEM & $\mathrm{RS}$ & Território nacional & Segurança pública \\
\hline PEC 235/2008 & $\begin{array}{l}\text { Deputado Mendes } \\
\text { Ribeiro Filho }\end{array}$ & PMDB & $\mathrm{RS}$ & Território nacional & Segurança pública \\
\hline PL 3084/2004 & $\begin{array}{l}\text { Deputado Murilo } \\
\text { Zauith }\end{array}$ & PFL & MS & Território nacional & Administrativo \\
\hline PL 6856/2006 & $\begin{array}{l}\text { Deputado Nelson } \\
\text { Proença }\end{array}$ & PPS & $\mathrm{RS}$ & Território nacional & Segurança pública \\
\hline PLC 116/2000 & $\begin{array}{l}\text { Deputado Osmar } \\
\text { Serraglio }\end{array}$ & PMDB & PR & Território nacional & $\begin{array}{l}\text { Econômico - } \\
\text { Política fundiária e } \\
\text { reforma agrária }\end{array}$ \\
\hline PLC 140/2001 & $\begin{array}{l}\text { Deputado Osmar } \\
\text { Serraglio }\end{array}$ & PMDB & PR & Território nacional & Administrativo \\
\hline PL 3105/2004 & $\begin{array}{l}\text { Deputado Osmar } \\
\text { Serraglio }\end{array}$ & PMDB & PR & Território nacional & $\begin{array}{l}\text { Econômico - } \\
\text { Política fundiária e } \\
\text { reforma agrária }\end{array}$ \\
\hline PEC 58/2003 & $\begin{array}{l}\text { Deputado Pedro } \\
\text { Henry }\end{array}$ & PPB & MT & Território nacional & $\begin{array}{l}\text { Econômico - } \\
\text { Política fundiária e } \\
\text { reforma agrária }\end{array}$ \\
\hline PL 59/2008 & $\begin{array}{l}\text { Deputado Pompeo } \\
\text { de Mattos }\end{array}$ & PDT & $\mathrm{RS}$ & Território nacional & Segurança pública \\
\hline PL 2817/2008 & $\begin{array}{l}\text { Deputado Renato } \\
\text { Molling }\end{array}$ & PP & $\mathrm{RS}$ & Território nacional & $\begin{array}{l}\text { Desenvolvimento } \\
\text { econômico e } \\
\text { regional }\end{array}$ \\
\hline PL 5978/2001 & $\begin{array}{l}\text { Deputado Salomão } \\
\text { Cruz }\end{array}$ & PFL & $\mathrm{RR}$ & Território nacional & $\begin{array}{l}\text { Econômico - } \\
\text { Política fundiária e } \\
\text { reforma agrária }\end{array}$ \\
\hline
\end{tabular}




\begin{tabular}{|c|c|c|c|c|c|}
\hline PL 2410/2007 & $\begin{array}{l}\text { Deputado Vieira da } \\
\text { Cunha }\end{array}$ & PDT & $\mathrm{RS}$ & Território nacional & $\begin{array}{l}\text { Desenvolvimento } \\
\text { econômico e } \\
\text { regional }\end{array}$ \\
\hline PLC89/2002 & $\begin{array}{l}\text { Deputado Wilson } \\
\text { Santos }\end{array}$ & PSDB & MT & Território nacional & $\begin{array}{l}\text { Econômico - } \\
\text { Política fundiária e } \\
\text { reforma agrária }\end{array}$ \\
\hline PLS 664/1999 & $\begin{array}{l}\text { Senador Alvaro } \\
\text { Dias }\end{array}$ & PV & PR & Território nacional & $\begin{array}{l}\text { Econômico - } \\
\text { Política fundiária e } \\
\text { reforma agrária }\end{array}$ \\
\hline PLS 93/2007 & $\begin{array}{l}\text { Senador Alvaro } \\
\text { Dias }\end{array}$ & PV & PR & Território nacional & $\begin{array}{l}\text { Econômico - } \\
\text { Política fundiária e } \\
\text { reforma agrária }\end{array}$ \\
\hline PLS 107/1992 & Senador César Dias & PMDB & $\mathrm{RR}$ & Território nacional & $\begin{array}{l}\text { Econômico - Minas } \\
\text { e energia }\end{array}$ \\
\hline PLS 403/2008 & $\begin{array}{l}\text { Senador Delcídio } \\
\text { do Amaral }\end{array}$ & PT & MS & Território nacional & $\begin{array}{l}\text { Econômico - Minas } \\
\text { e energia }\end{array}$ \\
\hline PLS 6/1997 & $\begin{array}{l}\text { Senador Ernandes } \\
\text { Amorim }\end{array}$ & PPB & $\mathrm{RO}$ & $\begin{array}{l}\text { Regiões Norte e } \\
\text { Oeste }\end{array}$ & $\begin{array}{l}\text { Desenvolvimento } \\
\text { agrícola e regional }\end{array}$ \\
\hline PL 7474/2002 & $\begin{array}{l}\text { Senador Jonas } \\
\text { Pinheiro }\end{array}$ & PFL & MT & Território nacional & $\begin{array}{l}\text { Econômico - } \\
\text { Política fundiária e } \\
\text { reforma agrária }\end{array}$ \\
\hline PLS 475/2003 & $\begin{array}{l}\text { Senador Jonas } \\
\text { Pinheiro }\end{array}$ & PFL & MT & Território nacional & $\begin{array}{l}\text { Econômico - } \\
\text { Política fundiária e } \\
\text { reforma agrária }\end{array}$ \\
\hline PLS 526/2011 & $\begin{array}{l}\text { Senador Jorge } \\
\text { Viana, Senadora } \\
\text { Ângela Portela, } \\
\text { Senador Anibal } \\
\text { Diniz e outros }\end{array}$ & & & Região norte & $\begin{array}{l}\text { Desenvolvimento } \\
\text { econômico e } \\
\text { regional }\end{array}$ \\
\hline PLS 688/1999 & $\begin{array}{l}\text { Senador Juvêncio } \\
\text { da Fonseca }\end{array}$ & PSDB & MS & Território nacional & $\begin{array}{l}\text { Econômico - } \\
\text { Política fundiária e } \\
\text { reforma agrária }\end{array}$ \\
\hline PLS 452/1999 & $\begin{array}{l}\text { Senador Mozarildo } \\
\text { Cavalcanti }\end{array}$ & PTB & $\mathrm{RR}$ & Território nacional & $\begin{array}{l}\text { Social - Direitos } \\
\text { humanos e minorias }\end{array}$ \\
\hline PEC 22/2009 & $\begin{array}{l}\text { Senador Osmar } \\
\text { Dias e outros }\end{array}$ & PDT & PR & Território nacional & Segurança pública \\
\hline PLS 545/2009 & $\begin{array}{l}\text { Senador Sérgio } \\
\text { Zambiasi }\end{array}$ & PTB & $\mathrm{RS}$ & Território nacional & $\begin{array}{l}\text { Desenvolvimento } \\
\text { econômico e } \\
\text { regional }\end{array}$ \\
\hline PLS 40/2010 & $\begin{array}{l}\text { Senador Sérgio } \\
\text { Zambiasi }\end{array}$ & PTB & $\mathrm{RS}$ & Região Sul & $\begin{array}{l}\text { Desenvolvimento } \\
\text { econômico e } \\
\text { regional }\end{array}$ \\
\hline PLS 38/2010 & $\begin{array}{l}\text { Senador Sérgio } \\
\text { Zambiasi }\end{array}$ & PTB & $\mathrm{RS}$ & Região Sul & $\begin{array}{l}\text { Desenvolvimento } \\
\text { econômico e } \\
\text { regional }\end{array}$ \\
\hline PEC 49/2006 & $\begin{array}{l}\text { Senador Sérgio } \\
\text { Zambiasi e outros }\end{array}$ & РTB & $\mathrm{RS}$ & Território nacional & Segurança pública \\
\hline $\begin{array}{l}\text { PLS 313/2008 } \\
\text { Mercosul }\end{array}$ & Sérgio Zambiasi & PTB & $\mathrm{RS}$ & Território nacional & $\begin{array}{l}\text { Desenvolvimento } \\
\text { econômico e } \\
\text { regional }\end{array}$ \\
\hline
\end{tabular}

Elaboração da autora a partir de dados coletados em: Rede de Informação Legislativa e Jurídica 
Analisando os nomes que aparecem de maneira repetida (mais de uma vez) na tabela nos permite identificar os atores mais ativos no tema, que ocupam lugares centrais na rede. Estes nomes são poucos: Sérgio Zambiasi (PTB/RS) com quatro projetos individuais e um coletivo; Osmar Serraglio (PMDB/PR) com três; e Luis Carlos Heinze (PP/RS), Jonas Pinheiro (PFL-DEM/MT) e Alvaro Dias (PV/PR) com dois. Notamos também a presença de Osmar Dias, irmão de Alvaro Dias, em um projeto de autoria coletiva. Um detalhamento dos assuntos dos projetos nos mostra que todos os projetos de autoria individual tratam de política fundiária ou de desenvolvimento econômico e regional; em quanto os dois projetos de autoria coletiva estão ligados a temas de segurança pública.

Em termos de regiões abrangidas, fora os projetos que se destinam a todo o território nacional ( $86 \%$ dos projetos), os únicos destinados especificamente à região Sul são de autoria de Sérgio Zambiasi (PTB/RS) e à região Norte são de autoria de Ernandes Amorim (PPB/RO). Desta maneira, existe uma coerência entre UF do proponente e região alvo do projeto. Entretanto, é possível notar que a metade dos projetos apresentados por comissões são direcionados à Amazônia.

O mapeamento dos temas tratados dentro dos projetos de lei conduzido na primeira parte deste trabalho, assim como a centralidade de certos assuntos nos projetos apresentados por membros do Congresso Nacional que são particularmente ativos no tema, torna interessante o cruzamento de dados relativos a outros grupos de interesse no Congresso Nacional para determinar a presença de possíveis interesses cruzados e laços entre grupos. O gráfico seguinte mostra o resultado desta análise conduzida pela autora a partir do cruzamento dos nomes de membros das frentes parlamentares ligadas a temas de agropecuária, de regularização fundiária, de segurança pública e de soberania nacional com os nomes dos autores de projetos de lei sobre temáticas fronteiriças. Também foram cruzados os nomes dos membros da Frente Parlamentar Mista para o Desenvolvimento de assuntos da faixa de fronteira, em existência durante um ano entre 2014 e 2015, com os nomes das quatro frentes parlamentares citadas previamente. 


\section{Gráfico 6: Rede de atores envolvidos em temas fronteiriços}

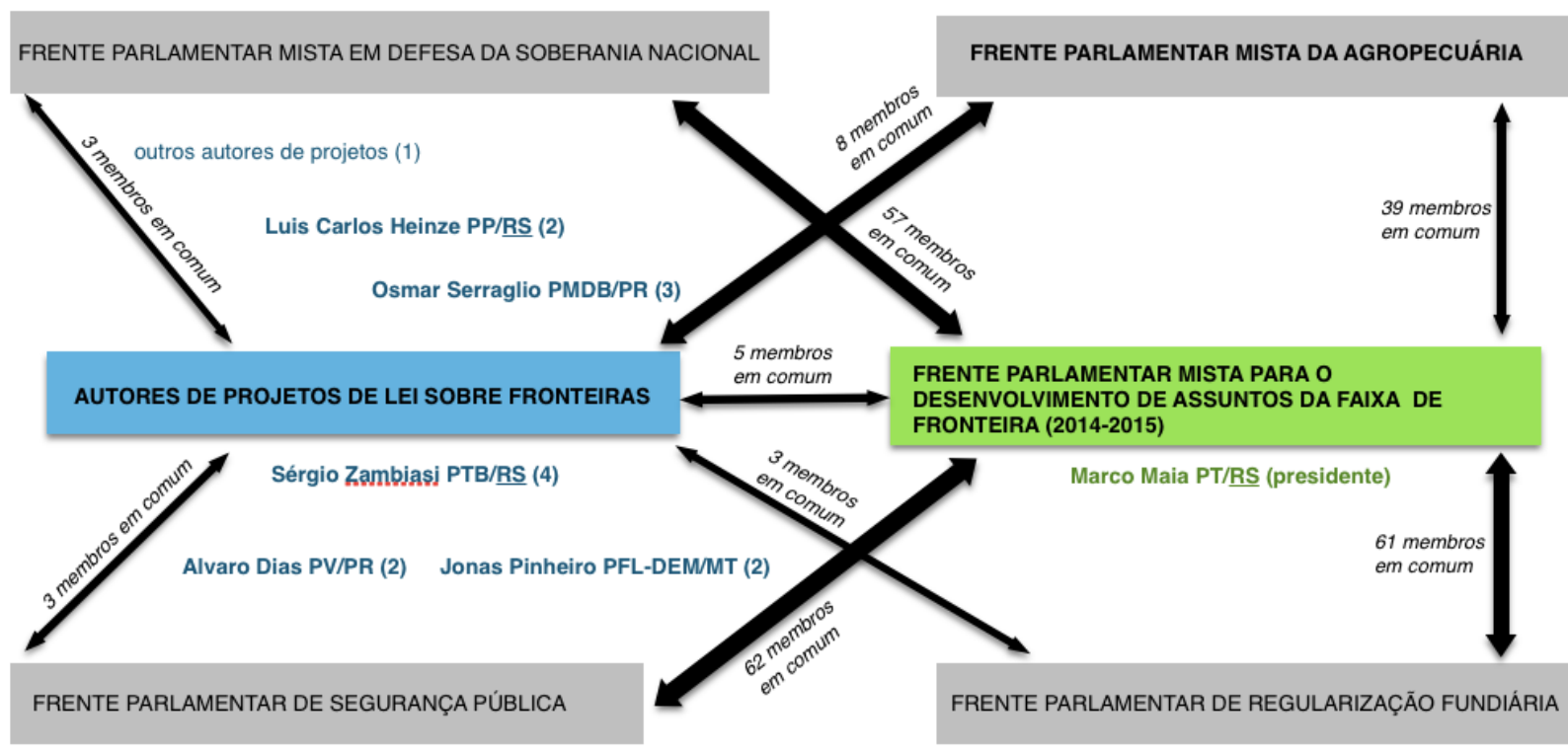

Elaboração da autora a partir de dados coletados em: CONGRESSO NACIONAL. Frentes

Parlamentares ${ }^{12}$; e obtidos junto à Assessoria de Comunicação da Frente Parlamentar da

Agropecuária $^{13}$

Este gráfico mostra, primeiramente, o laço forte que existe entre os autores de projetos de lei sobre fronteiras e a Frente Parlamentar Mista da Agropecuária: 8 membros desta frente foram autores de pelo menos um projeto ao longo do período estudado. As outras três Frentes parlamentares estudadas apresentam somente três membros em comum com autores de projetos de lei. Isto nos mostra um vínculo entre os temas e os grupos de interesse de fronteiras e de agropecuária, que pode ser o resultado de um cruzamento de interesses.

A Frente Parlamentar Mista para o Desenvolvimento de assuntos da faixa de fronteira também apresenta laços fortes com as outras quatro frentes estudadas. Entretanto, só cinco membros desta frente (do total de 209 membros) se encontram

\footnotetext{
12 Frente Parlamentar de regularização fundiária. Dados de 2015. Disponível em: $<$ http://www.camara.leg.br/internet/deputado/frenteDetalhe.asp?id=53564>

Frente Parlamentar de segurança pública. Dados de 2015. Disponível em: $\langle$ http://www.camara.leg.br/internet/deputado/frenteDetalhe.asp?id=53460 $>$

Frente Parlamentar Mista em defesa da Soberania Nacional. Dados de 2017. Disponível em: $<$ http://www.camara.leg.br/internet/deputado/frenteDetalhe.asp?id=53752 >

Frente Parlamentar Mista para o desenvolvimento de Assuntos da Faixa de Fronteira. Dados de 2014. Disponível em: <http://www.camara.leg.br/internet/deputado/frenteDetalhe.asp?id=53427>

Acessados em 01 de agos to de 2017.

13 Os dados usados na elaboração do gráfico são de 2015 para uma maior correspondência com os dados relativos a outras frentes.
} 
na lista de autores de projetos de lei sobre fronteiras. Desta forma, ela não aparenta ter reunido atores atuantes na área. Além disto, a curta duração da sua existência nos leva a descartar a relevância desta frente para o mapeamento da rede de atores envolvidos em questões fronteiriças.

Por fim, este gráfico confirma a posição, ao centro da rede, de membros do Congresso Nacional oriundos do Estado do Rio Grande do Sul. Entretanto, os atores posicionados em zonas centrais da rede apresentam uma heterogeneidade em termos de partido político. Os grupos de atores mais centrais na rede aparentam, assim, ser mais baseados em laços geográficos do que partidários.

\section{Conclusões}

Este estudo de caso permitiu trazer uma série de observações sobre a evolução da pauta fronteiriça no legislativo e sobre os atores envolvidos.

Primeiramente, foram distinguidas três fases em termos de números de projetos de lei submetidos ao Congresso Nacional sobre o tema das fronteiras: 1- De 1990 a 1998, o tema recebeu um nível de projetos de lei muito baixo; 2- De 1999 a 2009, teve um aumento brusco e importante no número de projetos sobre o tema; 3De 2010 a 2016, o tema perdeu espaço no legislativo, com um número de projetos de lei inferior ao período anterior.

Em segundo lugar, as categorias de assuntos tratados pelos projetos de lei variaram ao longo do período. Na primeira década do período de estudo (de 1990 a 1999), um número médio de temas foi tratado pelos projetos de lei, ficando principalmente no estabelecimento do marco jurídico para as fronteiras. Na segunda década (de 2000 a 2010), foi observada a entrada na pauta do tema do desenvolvimento econômico e regional, junto com a perda de espaço de assuntos administrativos e de política fundiária. Foi observado também um foco grande na questão da redução do tamanho da faixa de fronteira, objeto de vários projetos de lei. Por fim, na terceira década (de 2010 a 2016), foi constatado o recuo de questões de desenvolvimento agrícola e regional e o crescimento da pauta de desenvolvimento econômico e regional, deixando pensar que o desenvolvimento regional passou de estar ligado a questões agrícolas para questões econômicas. Também ficou claro que as questões fundiárias e de segurança não desapareceram da pauta. 
Em terceiro lugar, o estudo da presença dos diferentes Estados brasileiros nestas questões revela uma liderança destas questões por estados fronteiriços. Além disto, observa-se uma prevalência da região Sul na autoria dos projetos de lei, mais de $50 \%$ deles tendo sido propostos por deputados ou senadores daquela região. Entretanto, a região Sul não é mais representada em termos de destinatária específica dos projetos de lei. $O$ estudo dos partidos políticos mais envolvidos nesta questão revelou que os três principais deles são o PMDB, o PTB e o PFL/DEM.

O mapeamento dos atores centrais da rede ligada a temáticas fronteiriças no legislativo brasileiro revelou a existência de um laço forte entre esses últimos e a Frente Parlamentar da agropecuária, assim como de laços com as Frentes Parlamentares de regularização fundiária, de segurança pública e de soberania nacional. Também foi concluído que os atores ligados à Frente Parlamentar Mista para o Desenvolvimento de assuntos da faixa de fronteira em existência entre 2014 e 2015 não tem uma grande relevância na rede de temáticas fronteiriças. Por fim, os atores que constituem os nós mais centrais na rede corroboram a centralidade de membros do Congresso Nacional oriundos do Rio Grande do Sul na apresentação de projetos de lei sobre o tema. Entretanto, tem uma homogeneidade nos partidos políticos representados.

A hipótese inicial da autora era a de que no início dos anos 2000 se produziu uma mudança de agenda de questões administrativas e de segurança para questões de desenvolvimento; que a pauta legislativa de fronteiras é dominada por atores provindos da região Sul do Brasil; e que poderia existir uma ligação entre interesses ligados à agropecuária e às fronteiras. A primeira hipótese corresponde com o que está apontado na escassa literatura brasileira sobre o assunto (BRASIL, 2013; FURTADO, 2011; FURTADO, 2013). O levantamento de dados e estudo subsequente permitiu verificar empiricamente a veracidade desta afirmação. A segunda hipótese foi verificada no sentido de que foi observada uma forte prevalência de deputados e senadores da região Sul na autoria de projetos de lei sobre fronteiras. Portanto, não se nota uma prevalência de projetos de lei dirigidos especificamente para a região Sul. Por fim, a existência de uma ligação entre interesses relacionados à agropecuária e às fronteiras é sugerida pelo cruzamento de nomes entre os dois grupos de interesse.

Além disto, o estudo de caso permitiu colocar em relevo algumas dependências de trajetória que valem ser destacadas. Primeiramente, aparece uma 
dependência de trajetória na definição do tamanho da faixa de fronteira. O estudo da evolução do marco jurídico para as fronteiras brasileiras mostrou que o tamanho de 150 quilômetros a partir da linha divisória foi definido pela primeira vez em 1979 e reafirmado em dois textos de lei subsequentes (em 1980 e 1988). O nosso levantamento de dados também permitiu mostrar que entre 2003 e 2014, foram submetidos nove projetos de leis diferentes visando a reduzir o tamanho da faixa de fronteira mas apesar disso, o tamanho da faixa se manteve igual.

Em segundo lugar, o estudo permitiu mostrar que apesar da entrada da temática do desenvolvimento na agenda de fronteiras a partir do início dos anos 2000, questões de segurança e de política fundiária ficaram presentes até o final do período. Isso demonstra a existência de uma dependência de trajetória em termos de visão da fronteira como linha divisória a ser pensada em termos de segurança nacional, apesar da introdução de novos temas carregando uma visão da fronteira como zona.

Diante da escassez de literatura sobre o tema no campo da Ciência Política, este estudo procurou conduzir um trabalho inicial de mapeamento da atividade legislativa a propósito do tema ao longo do tempo. Ele também procurou identificar os atores e grupos envolvidos e apresentar as relações entre eles usando os instrumentos da abordagem de redes para identificar nós e laços. Com base neste trabalho inicial, seria interessante em um segundo tempo aprofundar a análise das motivações dos atores envolvidos e das relações entre eles, possivelmente fazendo ligações com o tema das fronteiras no executivo.

De tais estudos resultariam por certo indicadores interessantes com relação à capilaridade do assunto na agenda política nacional, para além do interesse eventualmente local ou regional, não raro vistos como insuficientemente representativos para que um tema como este se insira na agenda nacional do país.

\section{Referências}

ALBUQUERQUE, José Lindomar C. Fronteiras em movimento e identidades nacionais: A imigração brasileira no Paraguai. Tese (doutorado em Sociologia) Centro de Humanidades, Universidade Federal do Ceará, Fortaleza, 2005.

BONAFONT, Laura Chaquès. Redes de Políticas Públicas. Madrid: Centro de Investigaciones Sociológicas, 2004. 
BONAFONT, Laura Chaquès. Interest groups and agenda setting. In ZAHARIADIS, Nikolaos; BUCKMAN, Mertie. Handbook of Public Policy Agenda Setting. Cheltenham and Camberley: Edward Elgar Publisher, 2010.

BRASIL. Conselho de Defesa Nacional. Secretaria-Executiva. Seminário Faixa De Fronteira: Novos Paradigmas. Anexo 2.1.1 Brasília, 2011.

BRASIL. Ministério da Integração Nacional. Secretaria de Programas Regionais. Programa de Desenvolvimento da Faixa de Fronteira. Proposta de Reestruturação do Programa de Desenvolvimento da Faixa de Fronteira. Brasília. 2005. 418p. Disponível em: <http:// www.retis.igeo.ufrj.br/wp-content/uploads/2005-livroPDFF.pdf >. Acesso em: 24 junho 2017

BRASIL. Secretaria de Assuntos Estratégicos. Políticas de fronteira como fator de integração. Diagnóstico das ações brasileiras nos espaços de fronteira. Brasilia. 2013. $144 p$.

CALMON, Paulo; COSTA, Arthur Trindade Maranhão. Redes e governança das políticas públicas. RP3: Revista de Pesquisa em Políticas Públicas. v. 1, n. 1, julho, pp 1-29, 2013.

CARNEIRO FILHO, Camilo Pereira; LEMOS, Bruno de Oliveira. Brasil e Mercosul: iniciativas de cooperação fronteiriça. Boa Vista: ACTA Geográfica, Ed. Esp. Geografia Política e Geopolítica, pp.203-219, 2014. Disponível em: <http:// revista.ufrr.br/index.php/actageo/article/view/2448/1445>. Acesso em: 25 Junho 2017.

DAHL, Robert A. Who Governs?. New Haven, CT: Yale University Press, 1956.

FURTADO, Renata. O Estado Fragmentado: uma análise das elites organizacionais do Executivo federal e da abordagem da faixa de fronteira no Brasil. Dissertação (mestrado em Ciências Sociais) - Centro de Estudos e Pós-Graduação sobre as Américas, Universidade de Brasília, Brasilia, 2011.

FURTADO, Renata. Descobrindo a Faixa de Fronteira: A trajetória das elites organizacionais do executivo federal. As estratégias, as negociações e o embate da constituinte. Curitiba: Editora CRV, 2013. 392 p.

KOLIBA, Christopher; MEEK, Jack W.; ZIA, Asim. Governance Networks in Public Administration and Public Policy. Boca Raton: CRC Press, 2010. 388p.

LAZER, David. Networks in Political Science : Back to the Future. In Symposium on Political Networks. Political Science and Politics. 2011, pp. 61-68.

LOSADA, Paula Ravanelli; SADECK, Bruno. O papel da fronteira na integração regional: o caso do consórcio intermunicipal da fronteira. In PRADO, Henrique Sartori de Almeida; ESPÓSITO NETO, Tomaz [org.]. Fronteiras e relações internacionais. Curitiba: Ithala, 2015.

MACHADO, Lia Osorio. Limites, Fronteiras, Redes. In STROHAECKER T. M. et al. (org.). Fronteiras e Espaço Global. Porto Alegre: AGB, 1998.

MOREIRA, Marcelo Ribeiro et al. A Integração Transfronteiriça na Faixa de Fronteira: Limites e Possibilidades para a Ação do Ministério da Integração Nacional. In Boletim Regional. Informativo da Política Nacional de Desenvolvimento Regional. no 7 (maio/agosto). Brasília: Ministério da Integração Nacional. Secretaria de Políticas de Desenvolvimento Regional. 2008. 
NORTH, Douglas C. Institutions. The Journal of Economic Perspectives. Vol. 5, No. 1, pp. 97-112, 1991.

PIERSON, Paul. Politics in Time: History, Institutions, and Social Analysis. Princeton: Princeton University Press, 2004.

PERLIGER, Arie; BROOK, Suny Stony; PEDAHZUR, Ami. Social Network Analysis in the Study of Terrorism and Political Violence. In Symposium on Political Networks. Political Science and Politics. 2011.

PRADO, Henrique Sartori de Almeida; Espósito Neto, Tomaz [org.]. Fronteiras e relações internacionais. Curitiba: Ithala, 2015.

SCHERMA, Márcio Augusto. As fronteiras nas relações internacionais. In PRADO, Henrique Sartori de Almeida; ESPÓSITO NETO, Tomaz [org.]. Fronteiras e relações internacionais. Curitiba: thala, 2015.

SIEGEL, D. Social Networks in Comparative Perspective. In Symposium on Political Networks. Political Science and Politics. 2011.

STAUDT, Kathleen Border Politics in a Global Era. Comparative Perspectives. Lanham: Rowman \& Littlefield Publishers. 2017. 320 p. 